\title{
Research imperialism resurfaces in South Africa in the midst of the COVID-19 pandemic - this time, via a digital portal
}

The African continent is renowned for its excellent safaris. Tourists from around the world fly in, enjoy our warm hospitality, unparalleled landscapes and magnificent wildlife. And then they leave, with barely a hint that they were ever here. If we draw on this metaphor, it is not surprising that the terms 'safari research' and 'parachute research ${ }^{[1,2]}$ were coined, when foreign researchers did likewise: came to Africa, conducted research on unsuspecting communities, and left. Sometimes, like during the Ebola outbreak in West Africa, they left with biological samples too. ${ }^{[3,4]}$ Often, 'African researchers were left out of the full research process, invited to collaborate only as is useful for sample collection, but without any benefit of the research returning to support African researchers or infrastructure. ${ }^{[5]}$

What often resulted was a publication in a prestigious international journal (or a thesis or dissertation), authored by academics from the global north, ${ }^{[2,6,7]}$ replete with recommendations on how to do things better in Africa. Sometimes these foreign researchers were junior postgraduate students or research assistants. The paradox is that the reverse scenario of researchers from the global south conducting research involving data collection for their own academic benefit and professional advancement would neither be entertained nor tolerated in the global north. ${ }^{[8]}$

Mindful of the exploitative nature of such imperialistic research, the South African (SA) Ministry of Health, in its guidance on research, instituted measures to end safari research. The South African Good Clinical Practice (SAGCP) guideline ${ }^{[9]}$ made it mandatory that every biomedical research project had to be led by an SA principal investigator resident in the country and that all research in SA had to be approved by an SA research ethics committee (REC) registered with the National Health Research Ethics Council (NHREC). ${ }^{[10]}$

\section{Resurgence of imperialistic research}

Notwithstanding a fairly rigorous research regulatory environment in SA, an apparently legitimate research survey was posted in Medical Brief on 2 September 2020. ${ }^{[11]}$ At first glance, it appeared to be an interesting project initiated by the University of Kent, UK, seeking views of SA healthcare practitioners on abortion access and provision of services in public, private and non-governmental organisations. However, on closer inspection, it appeared as if there were no SA researchers involved and that the research had not been approved by an SA REC. Ideally, this matter ought to have been investigated by the NHREC. Given that this national body has been non-existent since November 2019, the absence of SA collaborators and the absence of local REC approval were confirmed in written correspondence with the researcher leading the study. A review of the title of the letter published in Medical Brief, 'University of Kent wants South African input on abortion project', underscores the colonialist tone of the project. Depleted of a benefit-sharing collaborative spirit, the study promised to ensure unidirectional flow of data out of Africa, once again.

The involvement of local RECs and collaboration with local researchers are important because a study on abortion access has significant potential for harm. Without adequate local contextualisation and input, there is a strong risk of increased harm to patients and service providers from such research, and it is possible that the findings may further limit access to legal abortions in SA. As a result, women who need to access abortion services may be further stigmatised.

\section{Digital platforms - a new data portal for biopiracy}

This attempt at a survey has given new meaning to the term 'safari research'. This time, a new portal to African data has been discovered and exploited. In the current era of online platforms, digital technology has removed the requirement to physically fly into Africa to conduct research. Data can now be extracted via a medical electronic newsletter like Medical Brief that reaches $\sim 46000$ healthcare professionals in SA! To maximise recruitment and data collection for the abortion study, the British researchers encouraged generous sharing of the survey on social media. Undoubtedly, electronic data collection and sharing has opened the floodgates for global misuse of research data from the global south. ${ }^{[12]}$

\section{Decolonising global health research}

Unconsented attempts at commercialisation and illegitimate sharing of African genomic data by the Wellcome Sanger Institute in the UK has recently drawn attention to unregulated cross-border transfer of data and the risks inherent in international collaborative research. ${ }^{[13]}$ Likewise, fair and equitable collaborative partnerships require diversity of authorship on publications and diverse representation at scientific conferences. Consequently, there have been numerous calls for the decolonisation of global health research. ${ }^{[14-16]}$ What rings true amid these calls are the wise words of Seve Abimbola: 'we can begin to truly decolonize global health by being aware of what we do not know, that people understand their own lives better than we could ever do, that they and only they can truly improve their own circumstances and that those of us who work in global health are only, at best, enablers.'[17]

\section{Conclusions}

Both the SAGCP guideline ${ }^{[9]}$ and the research ethics guidance ${ }^{[10]}$ from the Department of Health are in the process of revision. It is important that these guidelines incorporate ethical and legal issues related to digital health research so that all South Africans - participants, clinicians, academics, REC members, regulators, researchers and medical journal/newsletter editors - are acutely aware of potential loopholes in the system, as has been exposed by the abortion study in the latest issue of Medical Brief. The NHREC plays an indispensable role in guidance development and dissemination, as well as in provision of oversight of RECs in SA. It is therefore incomprehensible that the NHREC was not constituted in 2019. SA cannot continue to conduct research in the absence of a national research ethics body that is a crucial governance mechanism for protection of research participant rights.

\section{Keymanthri Moodley}

Centre for Medical Ethics and Law, Department of Medicine, Faculty of Medicine and Health Sciences, Stellenbosch University, Cape Town, South Africa

km@sun.ac.za

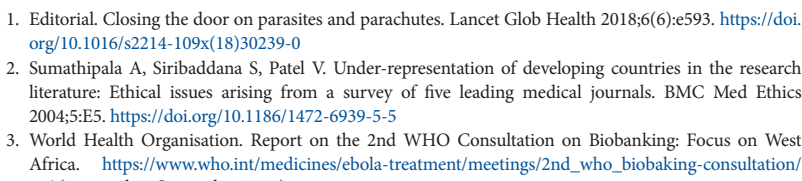
org/10.1016/s2214-109x(18)30239-0

2. Sumathipala A, Siribaddana S, Patel V. Under-representation of developing countries in the research literature: Ethical issues arising from a survey of five leading medical journals. BMC Med Ethics 2004;5:E5. https://doi.org/10.1186/1472-6939-5-5

3. World Health Organisation. Report on the 2nd WHO Consultation on Biobanking: Focus on West Africa. https://www.who.int/medicines/ebola-treatment/meetings/2nd_who_biobaking-consultation/ en/ (accessed 14 September 2020). 
4. Freudenthal E. Ebola's lost blood: Row over samples flown out of Africa as 'big pharma' set to cash in. The Telegraph, 6 February 2019. https://www.telegraph.co.uk/global-health/science-and-disease/ ebolas-lost-blood-row-samples-flown-africa-big-pharma-set-cash/ (accessed 5 September 2020)

5. Bentley AR, Callier SL, Rotimi CN. Evaluating the promise of inclusion of African ancestry populations

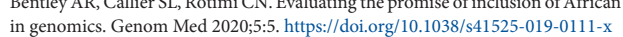

6. Iyer AR. Authorship trends in The Lancet Global Health. Lancet Glob Health 2018; 6(2):e142. https:// 6. Iyer AR. Authorship trends in The Lancet
doi.org/10.1016/S2214-109X(17)30497-7

7. Chaccour J. Authorship trends in The Lancet Global Health: Only the tip of the iceberg? Lancet Glob Health 2018;6(5):e497. https://doi.org/10.1016/S2214-109X(18)30110-4

Health 2018;6(5):e497. https://doi.org/10.1016/S2214-109X(18)30110-4
8. Pai M. Global health still mimics colonial ways: Here's how to break the pattern. The Conversation, Pai M. Global health still mimics colonial ways: Here's how to break the pattern. The Conversation,
2019. https://theconversation.com/global-health-still-mimics-colonial-ways-heres-how-to-break-the2019. https://theconversation.com/global-he

9. Department of Health. Guidelines for Good Practice in the Conduct of Clinical Trials with Human Participants in South Africa. Pretoria: DoH, 2006. http://www.kznhealth.gov.za/research/guideline2 pdf (accessed 14 September 2020).

10. Department of Health. Ethics in Health Research: Principles, Processes and Structures. Pretoria: DoH, 2015

11. University of Kent wants South African input on abortion project. Medical Brief. https://www. medicalbrief.co.za/archives/university-of-kent-wants-south-african-input-on-abortion-project/ (accessed 5 September 2020)
12. Moodley K. Africa's genetic material is still being misused. The Conversation, 2019. https://theconversation. com/africas-genetic-material-is-still-being-misused-128651 (accessed 5 September 2020).

3. Moodley K, Kleinsmidt A. Allegations of misuse of African DNA in the UK: Will data protection legislation in South Africa be sufficient to prevent a recurrence? Developing World Bioethics, 7 August legislation in South Africa be sufficient to

14. Kelaher M, Ng L, Knight K, Rahadi A. Equity in global health research in the new millennium: Trends in first-authorship for randomized controlled trials among low- and middle-income country researchers 1990 - 2013. Int J Epidemiol 2016;45(6):2174-2183. https://doi.org/10.1093/ije/dyw313

5. Adedokun BO, Olopade CO, Olopade OI. Building local capacity for genomics research in Africa: Recommendations from analysis of publications in sub-Saharan Africa from 2004 to 2013. Glob Health Action 2016;9:31026. https://doi.org/10.3402/gha.v9.31026

16. Chu KM, Jayaraman S, Kyamanywa P, Ntakiyiruta G. Building research capacity in Africa: Equity and global health collaborations. PLoS Med 2014;11(3):e1001612. https://doi.org/10.1371/journal. pmed. 1001612

17. Abimbola S. On the meaning of global health and the role of global health journals. Int Health 2018;10(2):63-65. https://doi.org/10.1093/inthealth/ihy010

S Afr Med J 2020;110(11):1068-1069. https://doi.org/10.7196/SAMJ.2020.v110i11.15285 